\title{
ROOM TEMPERATURE EPOXIDATION OF ALKENES WITH HYDROGEN PEROXIDE CATALYZED BY HETEROPOLYOXOMETALATE
}

\author{
Uday Sankar Agarwalla \\ Department of Chemistry, P. D. Women's College, Jalpaiguri-735101, West Bengal, India. \\ *E-mail: udaygrwlla@gmail.com
}

\begin{abstract}
Keggin-type heteropolyoxometalates have been explored as catalysts for the epoxidation of alkenes at room temperature. Alkenes have been catalytically oxidized to the corresponding epoxides using mild and environmentally benign hydrogen peroxide as terminal oxidant. For vanadium(V)-substituted heteropolyoxometalates $\left[\mathrm{H}_{\mathrm{x}-2} \mathrm{PV}_{\mathrm{x}} \mathrm{W}_{12-\mathrm{x}} \mathrm{O}_{40}\right]^{5-}(\mathrm{x}=4$ for POM 1 and 6 for POM 2), the efficiency of the catalyst towards epoxidation of alkenes is found to be dependent on the amount of vanadium atoms present in the POM catalyst and also on the nature of the reaction medium.
\end{abstract}

Key Words: Heteropolyoxometalate,Catalysis, Epoxidation, Alkene, Hydrogen Peroxide.

(C) RASĀYAN. All rights reserved

\section{INTRODUCTION}

Epoxidation of alkenes is of great significance, because epoxides play a significant role as useful intermediates in various organic syntheses ${ }^{1}$. Moreover, epoxides are also used in the production of drugs, paints, epoxy resins, pesticides and food additives ${ }^{2}$. Although catalytic epoxidation processes with various oxidants have been developed, a non-catalytic chlorohydrin process and homogeneously catalyzed processes in presence of $\mathrm{ROOR}^{\prime}$ or $\mathrm{RC}(=\mathrm{O}) \mathrm{OOH}$ as oxidant are well-known ${ }^{3-5}$. But these processes have major drawbacks from the environmental as well as economical point of view. Therefore, the development of efficient routes for catalytic epoxidation under mild conditions using inexpensive terminal oxidants remains as an important challenge in synthetic chemistry. Recently, catalytic epoxidation reaction in presence of hydrogen peroxide $\left(\mathrm{H}_{2} \mathrm{O}_{2}\right)$ as terminal oxidant has attracted much attention $^{6-13}$ because:

(i) It generates only water as a side product.

(ii) It contains the largest amount of active oxygen species among the known oxidants, and

(iii) It is inexpensive and not harmful to use than $\mathrm{ROOR}^{\prime}$ or $\mathrm{RC}(=\mathrm{O}) \mathrm{OOH}^{14}$.

This makes $\mathrm{H}_{2} \mathrm{O}_{2}$ the ideal oxidant from the viewpoint of green chemistry ${ }^{15}, 16$.

Polyoxometalates (POMs) are the polyoxoanions of the early transition metals and exhibit several characteristic features that make them suitable for applications in the fields of catalysis, biology, medicine, materials, electrochemistry, and photochemistry ${ }^{17-19}$. Among them, POMs play a significant role in the field of catalysis because their acidic and redox properties can be controlled at atomic or molecular levels ${ }^{20-24}$. Moreover, the inherent stability of POMs toward different terminal oxidants like dioxygen and hydrogen peroxide makes them attractive in catalysis. Accordingly the catalytic activity of POMs has received significant attention towards homogeneously catalyze selective oxidation reactions in presence of terminal oxidants. Various $\mathrm{H}_{2} \mathrm{O}_{2}$-based epoxidation reactions catalyzed by POMs have been developed ${ }^{25-30}$.

Herein, we wish to report the room temperature epoxidation of alkenes catalyzed by heteropolyoxometalate $\left[\mathrm{H}_{\mathrm{x}-2} \mathrm{PV}_{\mathrm{x}} \mathrm{W}_{12-\mathrm{x}} \mathrm{O}_{40}\right]^{5-}(\mathrm{x}=4$ for POM 1 and 6 for POM 2) with mild and benign 
$\mathrm{H}_{2} \mathrm{O}_{2}$ as terminal oxidant. The effect of a number of vanadium atoms in the heteropolyoxometalates towards alkene epoxidation has also been studied in this work.

\section{Materials and Methods}

\section{EXPERIMENTAL}

Chemicals used for the synthesis, alkenes used as substrates and the internal standard (pentafluoroiodobenzene) were purchased from Sigma Aldrich and were used directly. Solvents were distilled prior to epoxidation reaction following the known procedure ${ }^{31}$. The active oxygen content of $\mathrm{H}_{2} \mathrm{O}_{2}$ (as $\sim 30 \%$ solution in water) was measured by the iodometric method. The analysis of the catalytic product was performed by Perkin-Elmer Clarus-500 GC with FID (Elite-I, Polysiloxane, 15-meter column). The identification and quantification of the products were done from the response factors of standard product samples.

\section{Syntheses of Catalysts}

Potassium salt of the heteropolyoxometalates

Potassium salt of the heteropolyoxometalates, $\mathrm{K}_{5}\left[\mathrm{H}_{\mathrm{x}-2} \mathrm{PV}_{\mathrm{x}} \mathrm{W}_{12-\mathrm{x}} \mathrm{O}_{40}\right](\mathrm{x}=4$ and 6), were prepared following the known procedure ${ }^{32}$.

\section{Tetra-n-butylammonium (TBA) salt of the heteropolyoxometalates}

Tetra-n-butylammonium (TBA) salt of the heteropolyoxometalates, $\left[\left(\mathrm{C}_{4} \mathrm{H}_{9}\right)_{4} \mathrm{~N}\right]_{5}\left[\mathrm{H}_{\mathrm{x}-2} \mathrm{PV}_{\mathrm{x}} \mathrm{W}_{12-\mathrm{x}} \mathrm{O}_{40}\right](\mathrm{x}=4$ for POM 1 and 6 for POM 2) were synthesized and characterized according to the published method ${ }^{33}$.

\section{General Procedure for Epoxidation Reaction}

Catalytic epoxidations were performed under a nitrogen atmosphere in small screw-capped vials fitted with PTFE septa. In a typical reaction, the alkene substrate and the catalyst were dissolved in $2 \mathrm{~mL}$ of

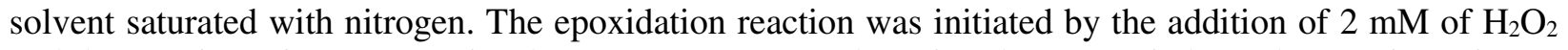
and the reaction mixture was stirred at room temperature by using the magnetic bar. The reaction mixture was analyzed periodically by GC. At the end of the reaction, an aliquot of $1 \mu \mathrm{L}$ from the reaction mixture was directly injected into a capillary column of a preheated GC after adding a standard solution of pentafluoroiodobenzene (PFIB) as an internal standard. The reaction products were identified and yield was measured by comparison of the response factors of standard product samples as usual.

\section{Catalytic Epoxidation of alkenes with $\mathrm{H}_{2} \mathrm{O}_{2}$}

\section{RESULTS AND DISCUSSION}

The TBA-salt of the heteropolyoxometalates (POM 1 and POM 2) have been explored as catalysts for the epoxidation of a group of alkenes at room temperature with environmentally benign $\mathrm{H}_{2} \mathrm{O}_{2}$ as oxidant under a nitrogen atmosphere.

\section{Epoxidation of Cyclooctene}

The catalytic activity of TBA-salt of heteropolyoxometalates has been examined initially in the epoxidation of cyclooctene, chosen as a model substrate, by $\mathrm{H}_{2} \mathrm{O}_{2}$ at room temperature (Scheme-1).

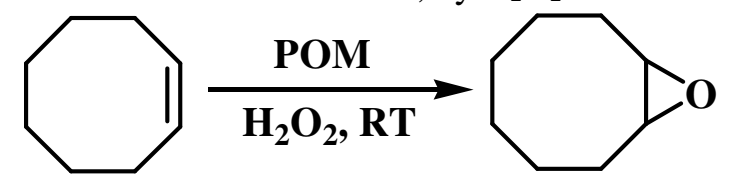

Scheme-1:Catalytic epoxidation of cyclooctene at room temperature.

\section{Effect of Solvent on the Catalytic Epoxidation Reaction}

Solvent plays a crucial role in the epoxidation of alkenes catalyzed by heteropolyoxometalates. The role of solvent in the catalytic epoxidation reaction was examined by performing the reaction in the solvents, 
viz., dichloromethane $\left(\mathrm{CH}_{2} \mathrm{Cl}_{2}\right)$, acetonitrile $\left(\mathrm{CH}_{3} \mathrm{CN}\right)$ and a mixture of acetonitrile and dichloromethane. Table-1 shows the POM 1 catalyzed epoxidation of cyclooctene with $\mathrm{H}_{2} \mathrm{O}_{2}$ in various solvent systems. All the reactions were carried out at least thrice, and the yields of epoxides reported represent the average obtained. The other parameters such as the concentration of substrate, catalyst,and $\mathrm{H}_{2} \mathrm{O}_{2}$ were kept constant in each solvent system.

Table-1: Room temperature epoxidation of cyclooctene by POM 1 in different solvents ${ }^{\mathrm{a}}$.

\begin{tabular}{ccc}
\hline Entry & Solvent & Yield $^{\text {b }}(\%)$ \\
\hline 1 & $\mathrm{CH}_{2} \mathrm{Cl}_{2}$ & 4 \\
\hline 2 & $\mathrm{CH}_{3} \mathrm{CN}$ & 5 \\
\hline 3 & $\mathrm{CH}_{3} \mathrm{CN} / \mathrm{CH}_{2} \mathrm{Cl}_{2}(2: 1, v / v)$ & 10 \\
\hline 4 & $\mathrm{CH}_{3} \mathrm{CN} / \mathrm{CH}_{2} \mathrm{Cl}_{2}(1: 1, v / v)$ & 22 \\
\hline 5 & $\mathrm{CH}_{3} \mathrm{CN} / \mathrm{CH}_{2} \mathrm{Cl}_{2}(1: 2, v / v)$ & 8 \\
\hline
\end{tabular}

${ }^{a}$ Reaction condition: cyclooctene $(100 \mathrm{mM})$, catalyst $(50 \mu \mathrm{M}), \mathrm{H}_{2} \mathrm{O}_{2}(2 \mathrm{mM})$

in $2 \mathrm{~mL}$ solvent, $4 \mathrm{~h}$. ${ }^{\mathrm{b}}$ Yields are based on the concentration of the oxidant.

The results reveal that epoxidation of cyclooctene strongly depends on the nature of the solvent. The catalyst was almost inactive in $\mathrm{CH}_{2} \mathrm{Cl}_{2}$ and $\mathrm{CH}_{3} \mathrm{CN}$. As it can be obtained from Table-1, a mixed solvent of $\mathrm{CH}_{3} \mathrm{CN}$ and $\mathrm{CH}_{2} \mathrm{Cl}_{2}$ in the $1: 1$ ratio $(v / v)$ proves to be an effective solvent for the cycloocteneepoxidation in terms of epoxide yield.

\section{Nature of Catalyst}

After choosing the best solvent system for the epoxidation reaction using POM 1 as catalyst, epoxidation of cyclooctene was next studied with POM 2 as catalyst under identical reaction conditions. The results are compiled in Table-2.

Table-2: Room temperature epoxidation of cyclooctene by POM 2 in different solvents ${ }^{\mathrm{a}}$.

\begin{tabular}{ccc}
\hline Entry & Solvent & Yield $^{\mathrm{b}}(\%)$ \\
\hline 1 & $\mathrm{CH}_{2} \mathrm{Cl}_{2}$ & 7 \\
\hline 2 & $\mathrm{CH}_{3} \mathrm{CN}$ & 8 \\
\hline 3 & $\mathrm{CH}_{3} \mathrm{CN} / \mathrm{CH}_{2} \mathrm{Cl}_{2}(2: 1, v / v)$ & 14 \\
\hline 4 & $\mathrm{CH}_{3} \mathrm{CN} / \mathrm{CH}_{2} \mathrm{Cl}_{2}(1: 1, v / v)$ & 36 \\
\hline 5 & $\mathrm{CH}_{3} \mathrm{CN} / \mathrm{CH}_{2} \mathrm{Cl}_{2}(1: 2, v / v)$ & 10
\end{tabular}

Reaction condition: cyclooctene (100 mM), catalyst $(50 \mu \mathrm{M}), \mathrm{H}_{2} \mathrm{O}_{2}(2 \mathrm{mM})$

in $2 \mathrm{~mL}$ solvent, $4 \mathrm{~h}$. ${ }^{b}$ Yields are based on the concentration of the oxidant.

It was found that cyclooctene was not epoxidized at all in the absence of POM catalyst under the similar reaction conditions showing that POMs have significant contribution in the epoxidation reaction.Moreover, the catalytic activity depends on the number of vanadium atoms in the catalyst. The epoxidation of cyclooctene with both the catalysts suggested that POM 2 exhibited better catalytic activity in terms of epoxide yield than POM 1 in all the solvents used. This suggested that a number of vanadium atoms in the heteropolyoxometalate catalyst plays a key role in the epoxidation by $\mathrm{H}_{2} \mathrm{O}_{2}$. Fig.- 1 shows the percentage yield of epoxide in different solvents by both the catalysts.

\section{Epoxidation of 1-Octene}

The notable feature of the present catalytic system is that non-activated terminal alkenes could be efficiently transformed to the corresponding epoxides in moderate yields. To examine the scope of the present epoxidation with regard to non-activated terminal alkenes, epoxidation of 1-octene was examined by TBA salt of POM (POM 1 and POM 2) with $\mathrm{H}_{2} \mathrm{O}_{2}$ under nitrogen atmosphere (Scheme-2).

Like cyclooctene, here also, a mixed solvent of $\mathrm{CH}_{3} \mathrm{CN}$ and $\mathrm{CH}_{2} \mathrm{Cl}_{2}$ in the $1: 1$ ratio $(v / v)$ afforded maximum epoxide yield. The epoxidation of 1-octene results 1,2-epoxyoctane in $17 \%$ conversion with 
POM 1/ $\mathrm{H}_{2} \mathrm{O}_{2}$ and in $26 \%$ with POM $2 / \mathrm{H}_{2} \mathrm{O}_{2}$. Here also, POM 2 exhibits better catalytic efficiency in terms of epoxide yield than POM 1.

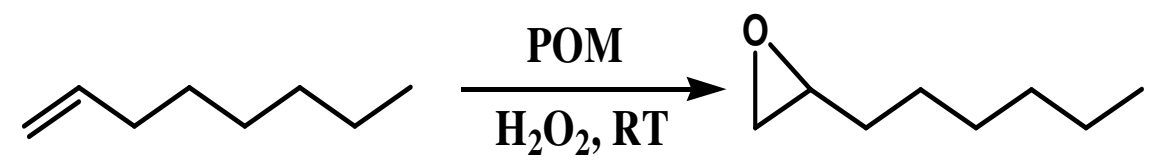

Scheme-2: Catalytic epoxidation of 1-octene at room temperature.

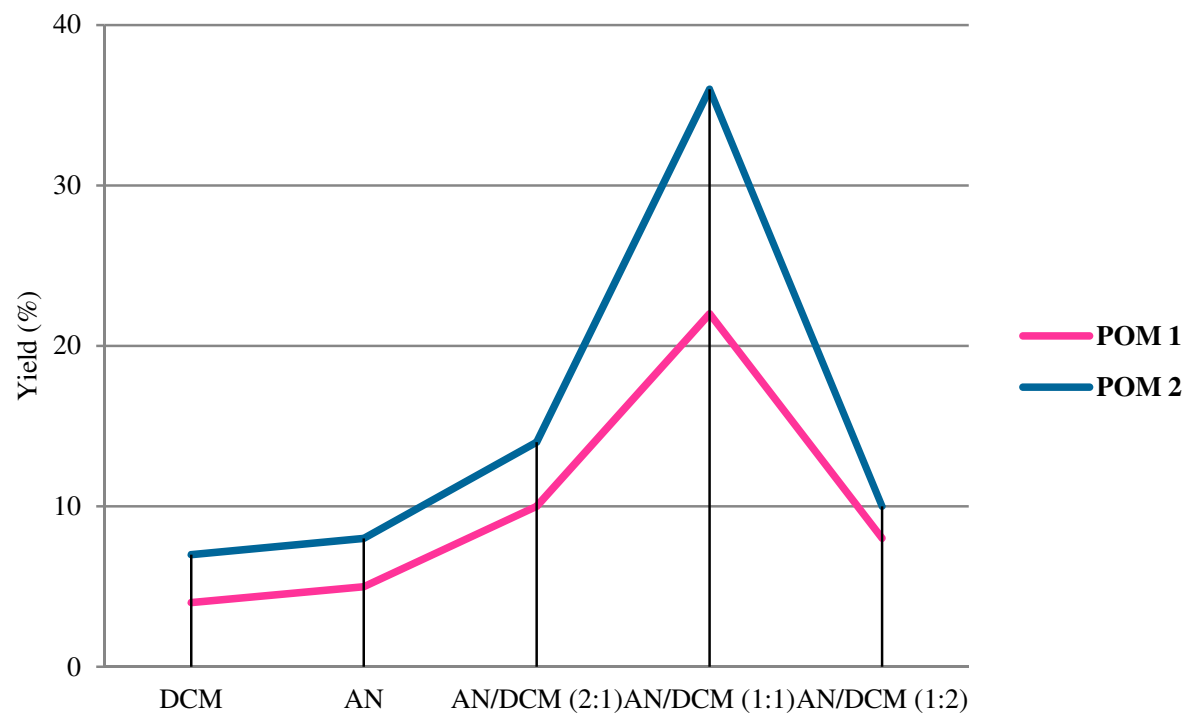

Fig.-1: the Relative yield of epoxide for cycloocteneepoxidation by POM 1 and POM 2, where DCM and AN stand for dichloromethane and acetonitrile respectively.

\section{Epoxidation of Other Alkenes}

The scope of the present epoxidation reaction catalyzed by TBA salt of POM (POM 1 and POM 2) with regard to other alkenes such as norbornene and dihydronaphthalene using environmentally benign $\mathrm{H}_{2} \mathrm{O}_{2}$ as oxidant was also examined under a nitrogen atmosphere at room temperature with the same reaction conditions. Among the $\mathrm{CH}_{2} \mathrm{Cl}_{2}, \mathrm{CH}_{3} \mathrm{CN}$ and a mixed solvent of $\mathrm{CH}_{3} \mathrm{CN}$ and $\mathrm{CH}_{2} \mathrm{Cl}_{2}, 1: 1$ mixture of $\mathrm{CH}_{3} \mathrm{CN}$ and $\mathrm{CH}_{2} \mathrm{Cl}_{2}(\mathrm{v} / \mathrm{v})$ was selected as the reaction medium because better conversion in the catalytic reaction in terms of epoxide yield was achieved. The results are compiled in Table-3.

Table-3: Room temperature epoxidation of alkenes by POM catalysts ${ }^{\mathrm{a}}$.

\begin{tabular}{c|c|c|c|c|c|c|}
\hline Entry & Substrate & Catalyst & $\begin{array}{c}\text { Product Yield } \\
(\%)^{\mathrm{b}}\end{array}$ \\
\hline 1 & & POM 1 & & \\
\hline
\end{tabular}

aReaction condition: substrate $(100 \mathrm{mM})$, catalyst $(50 \mu \mathrm{M}), \mathrm{H}_{2} \mathrm{O}_{2}(2 \mathrm{mM})$ in $2 \mathrm{~mL}$

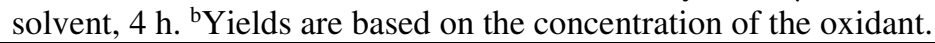


As shown in Table-3, norbornene is regiospecificallyoxidized to its exo-epoxide only. POM 2 with a greater number of vanadium atoms catalyzes the oxidation of norbornene with the yield of $62 \%$; however, the conversion decreases to $48 \%$ when POM 1 is used as catalyst (Table-3, entries 1,2).

The present $\mathrm{POM} / \mathrm{H}_{2} \mathrm{O}_{2}$ system also efficiently catalyzes the epoxidation of dihydronaphthalene at room temperature (Table-3, entries 3, 4). Here also POM 2 appears as a better catalyst than POM 1. By using POM 2, dihydronaphthalene is transformed to the corresponding epoxide with $66 \%$ yield whereas the yield decreases to 56\% using POM 1 as a catalyst. Thus, at room temperature, POM 2 exhibits better catalytic activity than POM 1 towards the epoxidation of alkenes at room temperature in presence of $\mathrm{H}_{2} \mathrm{O}_{2}$ as the terminal oxidant.

\section{Comparison of Efficiency of the Catalysts in the Epoxidation Reaction}

The efficiency of heteropolyoxometalate catalysts with a different number of vanadium atoms (POM 1 and POM 2) has also been examined. It has been found that a number of vanadium atoms in the POM catalysts has significant contribution in the epoxidation reaction by $\mathrm{H}_{2} \mathrm{O}_{2}$. It can be seen from the epoxidation of various alkenes (like cyclooctene, 1-octene, norbornene, anddihydronaphthalene) that the epoxide yield has been substantially increased when heteropolyoxometalate with a greater number of vanadium atoms (POM 2) was used as a catalyst.

\section{CONCLUSION}

The epoxidation of alkenes has been achieved at room temperature by heteropolyoxometalates as catalysts (POM 1 and POM 2) in presence of environmentally benign $\mathrm{H}_{2} \mathrm{O}_{2}$ as terminal oxidant. The choice of the reaction medium plays a significant role in the catalytic epoxidation reaction. Remarkable improvement in epoxide yield has been observed in a mixture of acetonitrile/dichloromethane $(1: 1, v / v)$ than in pure acetonitrile or in pure dichloromethane. The notable feature of the present catalytic system is that non-activated 1-octene has been efficiently epoxidized in moderate yield. The room temperature epoxidation of various alkenes under mild and environmentally friendly conditions seems promising for practical purposes.

\section{ACKNOWLEDGEMENT}

The financial support from UGC for Minor Research Project [No. F.PSW-197/15-16 (ERO)] is gratefully acknowledged. The author would also like to convey his sincere gratitude to Dr. P. Bandyopadhyay, Department of Chemistry, the University of North Bengal for his support.

\section{REFERENCES}

1. R.A.Sheldon and J.K. Kochi,Metal-Catalyzed Oxidations of Organic Compounds, Academic Press: New York (1981)

2. K. Bauer, D.Garbeand H. Surburg, Common Fragrance and Flavor Materials, Wiley/VCH, New York/Weinheim(1997)

3. C.L. Hill, Advances in Oxygenated Processes (Ed.: A. L. Baumstark) JAI Press, Inc., London,1(1) (1988)

4. M. Hudlucky, Oxidations in Organic Chemistry,ACS Monograph Series, American Chemical Society, Washington DC (1990)

5. K.A. Joergensen, Chem. Rev.,89, 431 (1989), DOI:10.1021/cr00093a001

6. C. Venturello, E.Alneriand M.Ricci, J. Org. Chem.,48, 3831 (1983), DOI: 10.1021/jo00169a052

7. Y. Ishii, K. Yamawaki, T. Ura, H. Yamada, T. Yoshida and M. Ogawa, J. Org. Chem.,53,3587 (1988), DOI: 10.1021/jo00250a032

8. K. Sato, M. Aoki, M. Ogawa, T. Hashimoto, D.Panyellaand R. Noyori, Bull. Chem. Soc. Jpn.,70, 905 (1997), DOI: $10.1246 /$ bcsj.70.905

9. B.S. Lane, M. Vogt, V.J.DeRoseand K.Burgess, J. Am. Chem. Soc.,124,11946 (2002), DOI: $10.1021 / \mathrm{ja} 025956 \mathrm{j}$ 
RASĀYAN J. Chem.

Vol. 11 | No. 2 I756 - 761 | April - June | 2018

10. M.C. White, A.G.Doyle and E.N. Jacobsen, J. Am. Chem. Soc.,123, 7194 (2001), DOI: $10.1021 / \mathrm{ja} 015884 \mathrm{~g}$

11. B.S.Lane and K. Burgess, Chem. Rev.,103, 2457 (2003), DOI:10.1021/cr020471z

12. P. Jiménez-Lozano, I.Y.Skobelev, O.A.Kholdeeva, J.M.Pobletand J.J.Carbó, Inorg. Chem.,55(12), 6080(2016), DOI: 10.1021/acs.inorgchem.6b00621

13. V. Sharma and P. Sagar, Rasayan J. Chem., 3 (1), 16 (2010)

14. P.T.Anastasand J.C.Warner, Green Chemistry: Theory and Practice,Oxford University Press(1998)

15. S.K. Sharma, A. Chaudhary and R.V. Singh, Rasayan J. Chem., 1 (1), 68 (2008)

16. S. Sharma, S. Gangal and A. Rauf, Rasayan J. Chem., 1 (4), 693 (2008)

17. D.E. Katsoulis, Chem. Rev.,98, 359 (1998), DOI:10.1021/cr960398a

18. N.Mizuno and M.Misono,Chem. Rev.,98, 199 (1998), DOI: 10.1021/cr960401q

19. I.V.Kozhevnikov,Chem. Rev.,98, 171 (1998), DOI:10.1021/cr960400y

20. T. Okuhara, N.Mizuno and M. Misono, Adv. Catal.,41,113, (1996), DOI:10.1016/S03600564(08)60041-3

21. C.L.Hill and C.M. Prosser-McCartha, Coord. Chem. Rev.,143, 407 (1995), DOI:10.1016/00108545(95)01141-B

22. C.L. Hill, In Comprehensive Coordination ChemistryII;J.A.Mc-Clevertyand T.J.Meyer Eds.; Elsevier: Amsterdam, The Netherlands,4, 679 (2003)

23. I.V.Kozhevnikov, Catalysis by Polyoxometalates, John Wiley \& Sons, Ltd: Chichester, England (2002)

24. M.T.Pope,In Comprehensive Coordination Chemistry II, (Eds.: J. A. McCleverty and T.J. Meyer) Elsevier, Amsterdam,4, 635 (2003)

25. N. Mizuno, K.Yamaguchi and K. Kamata, Coord. Chem. Rev.,249, 1944 (2005), DOI: 10.1016/j.ccr.2004.11.019

26. D.C. Duncan, R.C. Chambers, E.Hecht and C.L. Hill,J. Am. Chem. Soc.,117,681 (1995), DOI: 10.1021/ja00107a012

27. Y. Ding, W. Zhao, H. Hua and M.Baochun, Green Chem.,10, 910 (2008), DOI: 10.1039/B808404A

28. R.Tayebee, Asian J. of Chem.,20 (1), 8 (2008)

29. E. Tebandeke,H.Ssekaaloand O.F. Wendt, African Journal of Pure and Applied Chemistry,7(2), 50 (2013), DOI: 10.5897/AJPAC12.060

30. H.Salavatiand A.Teimouri, Int. J. Electrochem. Sci.,12,7829 (2017), DOI: 10.20964/2017.08.20

31. W.L.F.Armaregoand D.D. Perrin, Purification of Laboratory Chemicals, $4^{\text {th }}$ ed., Pergamon Press, Oxford, England (1997)

32. D.P.Smith and M.T.Pope, Inorg. Chem.,12,331 (1973), DOI: 10.1021/ic50120a018

33. U.S. Agarwalla, Silpakorn U Science \& Tech J.,11 (3), 25 (2017)

[RJC-3029/2018] 